\title{
RIDGE-RUNNEL MIGRATION
}

\author{
Jens Figlus ${ }^{1}$, Nobuhisa Kobayashi ${ }^{2}$ and Christine Gralher $^{2}$
}

\begin{abstract}
The recovery of beaches after a storm can be influenced significantly by ridge-runnel migration. Ridges are made up of large volumes of sand which is important for the coastal sediment budget. The experiment described in this paper gives an insight into the complex hydrodynamics and sediment transport mechanisms related to onshore ridge-runnel migration. Detailed water free surface elevation, fluid velocity and sediment transport rate measurements were taken in a mobile bed wave flume with a focus on the effect of water ponding and runnel drainage on the profile evolution. The measured results have been used to calibrate the time-averaged numerical cross-shore model CSHORE. The model has the capability to deal with the effect of a pronounced profile depression (water-filled runnel) forming on the intermittently wet and dry zone of the beach. Results of the experiment compared with the corresponding numerical model computations show that the rapid onshore migration of a ridge-runnel system under fairly energetic wave conditions can be computed with CSHORE but further improvements of the model are necessary.
\end{abstract}

Keywords: beach recovery; beach morphology; moveable bed experiment; sediment transport; numerical modeling; ridge and runnel; morphodynamics; profile evolution

\section{INTRODUCTION}

\section{Background}

This paper deals with coastal ridge-runnel migration which can play a significant role in beach recovery after storms. Ridge-runnel systems comprise shore-parallel sand crests and water filled troughs and are visible on many of the world's beaches. They are present in the intermittently wet and dry zone of the beach profile where fluctuating water levels and waves constantly reshape their appearance. Ridge-runnel systems are dynamic coastal morphology features with important implications not only for beach recovery after storms but also for the coastal sediment budget in general due to their large volumes of sand being set in motion by wave action.

Several processes contribute to the migration of ridge-runnel systems. The ridge crest is overtopped by waves and moved onshore as water and sediment are deposited inside the runnel. The runnel acts as a settling basin for the incoming sediment since the flow velocities in the runnel are small compared to the velocity of the overtopping waves on the ridge crest. As the water level in the runnel increases, an offshore return flow out of the ridge is initiated allowing water and sediment to exit the runnel. The offshore return of water and sediment can occur over the ridge crest or through rip channels intersecting the ridge at specific locations. It becomes evident that the simultaneous occurrence of the onshore directed overtopping flow initiated by waves and the offshore return flow out of the runnel creates a highly complex sediment transport situation.

\section{Existing Capabilities and Literature Review}

The complicated sediment transport processes responsible for ridge-runnel evolution are still only poorly understood and modeling capabilities remain limited. This may be attributed in part to the complex interaction of the hydrodynamic forcing and the morphological response, but also to the limited amount of associated field and laboratory data. Especially the collection of hydrodynamic data on ridge crests with only intermittently occurring, very shallow water flows is challenging.

Hence, quantitative field and laboratory data on ridge-runnel migration are scarce. Most existing field investigations are confined to a specific location and short time periods (not more than a few tide cycles). Numerous qualitative observations of related phenomena have been reported but detailed measurements of wave motion, flow velocities, sediment transport rates and profile changes are rare. Ridge-runnel systems appear in the literature under various names mostly related to intertidal bars. The common feature of these sand waves and bars is that at some point during the tide cycle the crest becomes exposed and a ridge-runnel system forms. Masselink et al. (2006) gave an overview of available field observations. They categorized intertidal bars into three different regimes according to their scale. Slip face bars are the largest intertidal bar feature and make up the first regime. Low amplitude ridges are more subdued morphological forms and fall into the second regime. Sand waves

\footnotetext{
${ }^{1}$ Maritime Systems Engineering Department, Texas A\&M University at Galveston, 200 Seawolf Parkway, Galveston, TX 77553, USA, E-mail: figlusj@tamug.edu

${ }^{2}$ Center for Applied Coastal Research, Department of Civil and Environmental Engineering, University of Delaware, 259 Academy Street, Newark, DE 19716, USA
} 
represent relatively marginal repetitive features making up the third regime. The ridge-runnel experiment carried out in the present investigation pertains to the slip-face category. Masselink et al. (2006) pointed out the dominant importance of tidal water level variations and wave processes in shallow water depths for the evolution of such features. They qualitatively described hydrodynamic and sediment transport processes and their morphological response.

Several authors discussed field measurements of onshore migrating intertidal bars. Robin et al. (2009) measured morphological changes, hydrodynamics and sediment tracer movement for one intertidal bar located in an ebb delta inlet system. They carried out four short experiments (one tide cycle each) under different wave and tide conditions. Their observed ridge-runnel system (slip-face bar type) exhibited onshore migration on the order of $1 \mathrm{~cm} / \mathrm{min}$ during high-energy wave conditions. No movement was registered during calm periods. The migration occurred at times in the tide cycle when the ridge-runnel system was located in the shoaling, surf, and swash regimes. Houser and Greenwood (2007) reported onshore migration of a ridge-runnel system (swash bar) during a storm on the Danish coast (two tide cycles). They explained the migration by the gradient in the fluid acceleration skewness. Aagaard et al. (2006) observed onshore migration of an intertidal bar over four tide cycles and compared the difference in sediment transport and circulation patterns before and after the runnel had filled. Vincent and Green (1990) measured suspended sand concentration profiles and velocities near the crest of a ridge-runnel system on an English beach. Two 12-min time series were recorded in a nonbreaking wave regime where onshore-skewed wave-induced flows close to the bed were found to be responsible for the shoreward flux of sand.

Numerical approaches to ridge-runnel migration varied tremendously depending on desired detail and represented time scale. Since our main interest pertains to the daily to monthly evolution of beach profiles and related engineering applications we will not focus on detailed wave-resolving models. A review by de Vriend et al. (1993) shed light on several mathematical approaches to long-term coastal morphology modeling. They explained models based on statistical extrapolation of past coastal behavior, semi-empirical models, and models using formally integrated representations of inherent small-scale processes. The common goal is to reduce computational effort by eliminating details that may not be important for long-term morphology predictions. This leads to the creation of more transparent and stable models. Masselink (2004), for example, introduced a morphodynamic model to predict the behavior of multiple intertidal bars. They employed a sinusoidal sediment transport shape function shifted along the beach profile with regard to the tide level. In their formulation the runnels acted as a sediment transport barrier which is supposed to simulate attenuation effects. The cited work shows that ridge-runnel systems are in fact an important morphological feature because they affect the sediment transport patterns in the intermittently wet and dry zone significantly.

\section{Scope of this Study}

We conducted a ridge-runnel physical model experiment in a movable-bed wave flume to investigate the migration of these morphological features in a controlled laboratory setting. For the present study, two laboratory tests representing two different return flow scenarios were conducted. Fig. 1 displays schematic drawings and photos of the two scenarios. Scenario 1 consists of a ridge runnel system in which water and sediment collected in the runnel can drain either via offshore backflow over the ridge or through a rip channel (top left panel and bottom left photo of Fig. 1). For scenario 2, offshore return flow of sediment and water are only possible via backflow over the ridge (top right panel and bottom right photo of Fig. 1).

Measurements of high-resolution profile changes, overwash transport rates, shallow water flow velocities and free surface elevation along the flume and in the intermittently wet and dry zone allowed for the creation of a unique ridge-runnel migration data set and formed the basis for numerical comparison. The experimental results have been used to calibrate the process-based cross-shore numerical model CSHORE which has been extended to a ridge-runnel system. The experiment was designed specifically to reproduce onshore migration of the most pronounced ridge-runnel type (slipface bar) under fairly energetic wave conditions. Since evidence from field measurements suggests that active ridge migration occurs mainly while the crest is emergent (e.g. Robin et al., 2009), a constant still water level seaward of the ridge was adopted in the experiment.

Figlus et al. (2012) provided a detailed analysis of the experiment data and the numerical model comparison. This paper is intended to supplement that information by giving further detail about the experiment setup, the data analysis and the numerical model extension for ridge-runnel migration. 

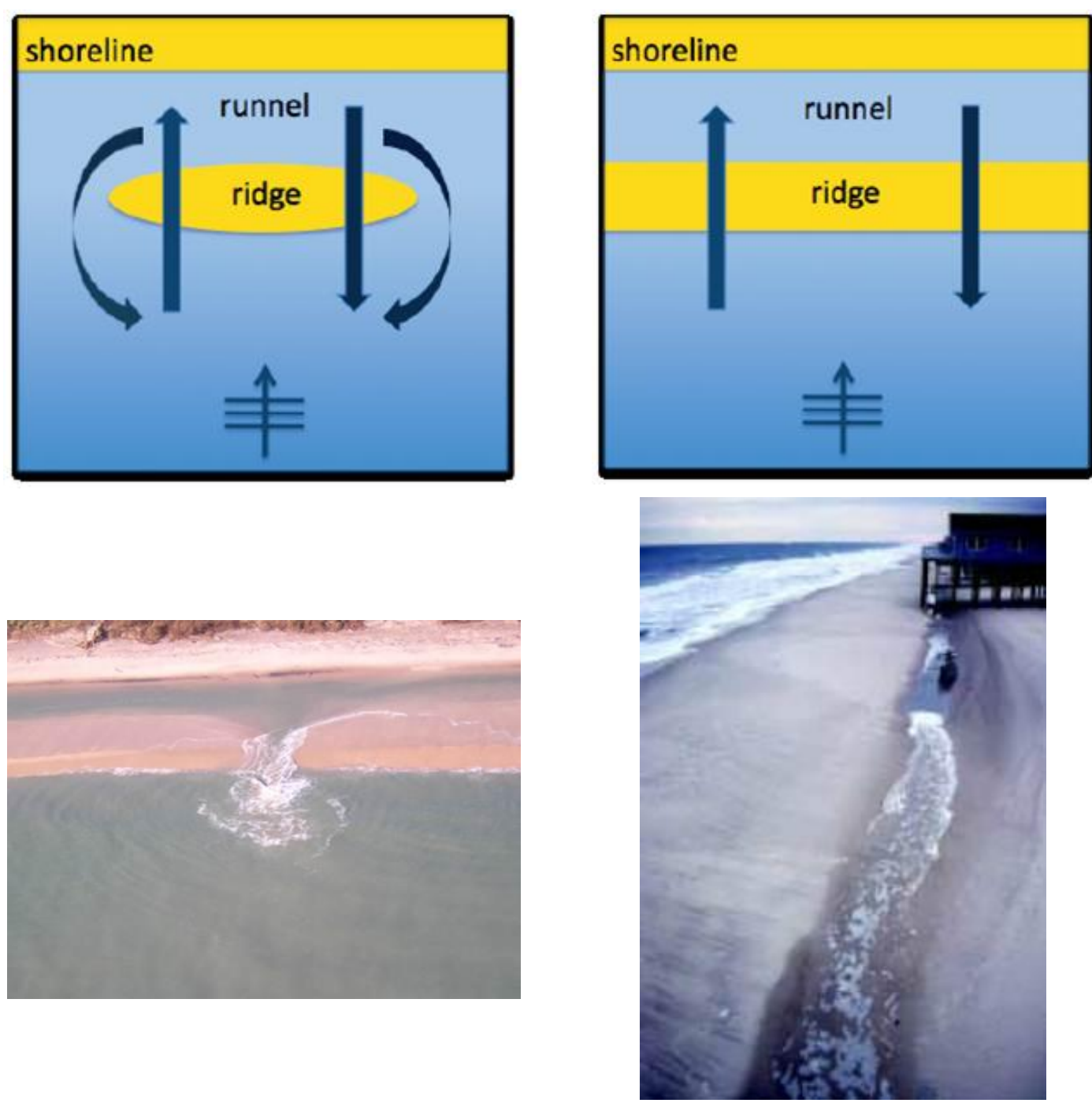

Figure 1. Top left panel: Schematic of ridge-runnel scenario 1 with possible offshore return flow of water and sediment over the ridge crest and via rip channels intersecting the ridge. Bottom left panel: Photo of a ridge-runnel system intersected by a rip channel at Vero Beach, FL (photo by NOAA). Top right panel: Schematic of ridge runnel scenario 2 with possible offshore return flow of water and sediment over the ridge crest only. Bottom right panel: Photo of a longshore uniform ridge-runnel system at South Bethany, DE (photo by DNREC).

\section{EXPERIMENT DESCRIPTION}

\section{Flume Setup}

Two different initial ridge-runnel profiles were constructed with fine sand $\left(d_{50}=0.18 \mathrm{~mm}\right)$ in a 23 $\mathrm{m}$ long and $1.15 \mathrm{~m}$ wide section of the University of Delaware's Sand Tank before being exposed to identical irregular wave conditions. Simulating the two scenarios displayed in Fig. 1 in an essentially two-dimensional wave flume requires a few simplifications. Fig. 2 shows a side view of the two initial profiles in the sand flume with a fixed-height back wall to represent the two scenarios. The High Ridge (HR) setup in the left panel mimics the combined runnel drainage through rip channels and backflow over the ridge by allowing wave overtopping over the vertical wall at the landward end of the profile in addition to the offshore flow of water and sediment over the ridge crest. High ridge pertains to the fact that the initial ridge crest is higher than the vertical wall crest. The LR or Low Ridge test (right panel), on the other hand, simulates the second scenario by preventing wave overtopping over the vertical wall. In this case only offshore return flow over the ridge is possible. The entire profile including the water level was lowered in the LR test to prevent wave overtopping over the vertical wall. 


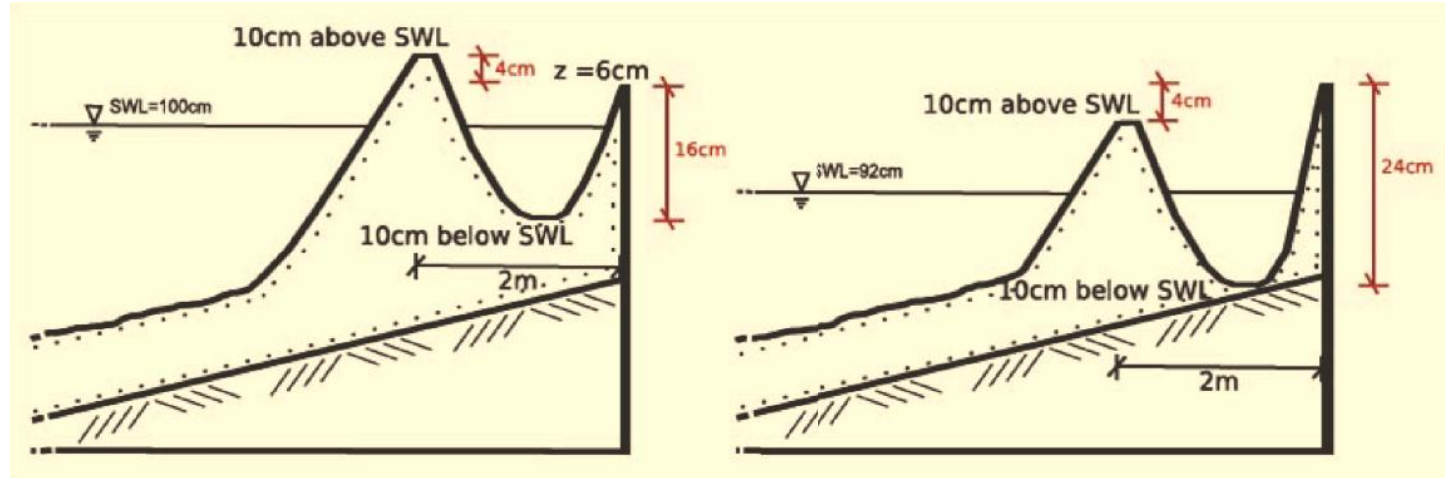

Figure 2. High Ridge (HR) and Low Ridge (LR) initial setup. The initial HR (LR) ridge crest is situated $4 \mathrm{~cm}$ above (below) the vertical wall crest.

A schematic of the general setup for the ridge-runnel experiment is given in Fig. 3. It should be noted that only a section of the entire wave tank $(L=30 \mathrm{~m}, W=2.5 \mathrm{~m}, H=1.5 \mathrm{~m})$ was used for the experiment to reduce the amount of required sand and to limit the development of seiching modes. A piston-type wave maker generated 400-s bursts of irregular waves corresponding to a TMA spectrum. Each test comprised a number of the same bursts, each burst identified by its run number starting from run number 0 for the initial profile. The spectral significant wave height and peak period measured for the combination of incoming and reflected wave trains were $18 \mathrm{~cm}$ and $2.6 \mathrm{~s}$, respectively.

Along the centerline of the flume section, eight capacitance wave gauges (WG1-WG8) measured the free surface elevation $\eta$ above the still water level (SWL). The vertical coordinate $z$ is positive upward with $z=0$ at SWL and the origin of the onshore coordinate $x$ is chosen at the WG1 location. Wave gauges WG1-8 were located at $x=0.0,0.25,0.95,8.3,14.9,17.0,18.5$, and $19.5 \mathrm{~m}$. Gauges WG7 and WG8 were placed inside the runnel of the initial HR and LR profiles to measure $\eta$ and the changing runnel water level (RWL) at these cross-shore locations during the onshore migration of the ridge. These locations in particular showed rapid profile changes as indicated by preliminary test runs, which is why WG7 and WG8 were partially buried in the sand to avoid possible exposure to air.

Two $20 \mathrm{~Hz}$ Sontek acoustic Doppler velocimeters (ADV) and an additional $200 \mathrm{~Hz}$ Nortek Vectrino for the LR test recorded flow velocities at strategic locations in front and on top of the ridge and in the runnel. The additional Vectrino probe was placed in the intermittently wet and very shallow water region on the passing ridge crest for the LR test. ADV1 was a downward looking 3D probe positioned next to WG5 at 2/3 of the local water depth below SWL and ADV2 was a side-looking 2D probe at the WG8 cross-shore location with its measuring volume half of the local water depth below RWL or approximately $1 \mathrm{~cm}$ above the local bottom on the sloping beach after the runnel had disappeared. The Vectrino was a side-looking 3D instrument next to WG7 where water depths were very small over the passing ridge crest. Its measuring volume was about $1 \mathrm{~cm}$ above the local bottom. All instruments were sampled at $20 \mathrm{~Hz}$ except the Vectrino which was sampled at $200 \mathrm{~Hz}$ and used only for the LR test.

As detailed in Fig. 2, the HR and LR tests had similar initial ridge-runnel shapes with crest and trough elevations of $10 \mathrm{~cm}$ above and $10 \mathrm{~cm}$ below SWL, respectively. Ridge crest and runnel trough were $1 \mathrm{~m}$ apart in the cross-shore direction and a low-crested vertical wall was located $1 \mathrm{~m}$ landward of the trough. Well-sorted fine sand with a median diameter $d_{50}=0.18 \mathrm{~mm}$ was placed on top of a $1 / 30$ plywood slope with a sand layer thickness of at least $30 \mathrm{~cm}$ outside the runnel. The measured specific gravity of the placed sand was 2.6 , its porosity was 0.4 and its fall velocity was $2.0 \mathrm{~cm} / \mathrm{s}$.

For the HR test the water depth in front of the wave maker was $100 \mathrm{~cm}$ and the initial ridge crest was $4 \mathrm{~cm}$ higher than the wall at the landward end of the runnel. Thus, the drainage effect was achieved by wave overtopping and sediment overwash of the wall once the runnel was filled with overtopped water from the incident waves. Water and sediment transported over the vertical wall during each 400-s run were collected in a basin and measured after each run. A sand trap made from polyester fabric mesh with a micron rating of 74 retained grain diameters exceeding $0.074 \mathrm{~mm}$ and allowed water to pass through. The collection basin included a water recirculation system consisting of a pump, a flow meter, pipes, and a valve to maintain a constant SWL in the $2.5-\mathrm{m}$ wide wave tank during each run. 


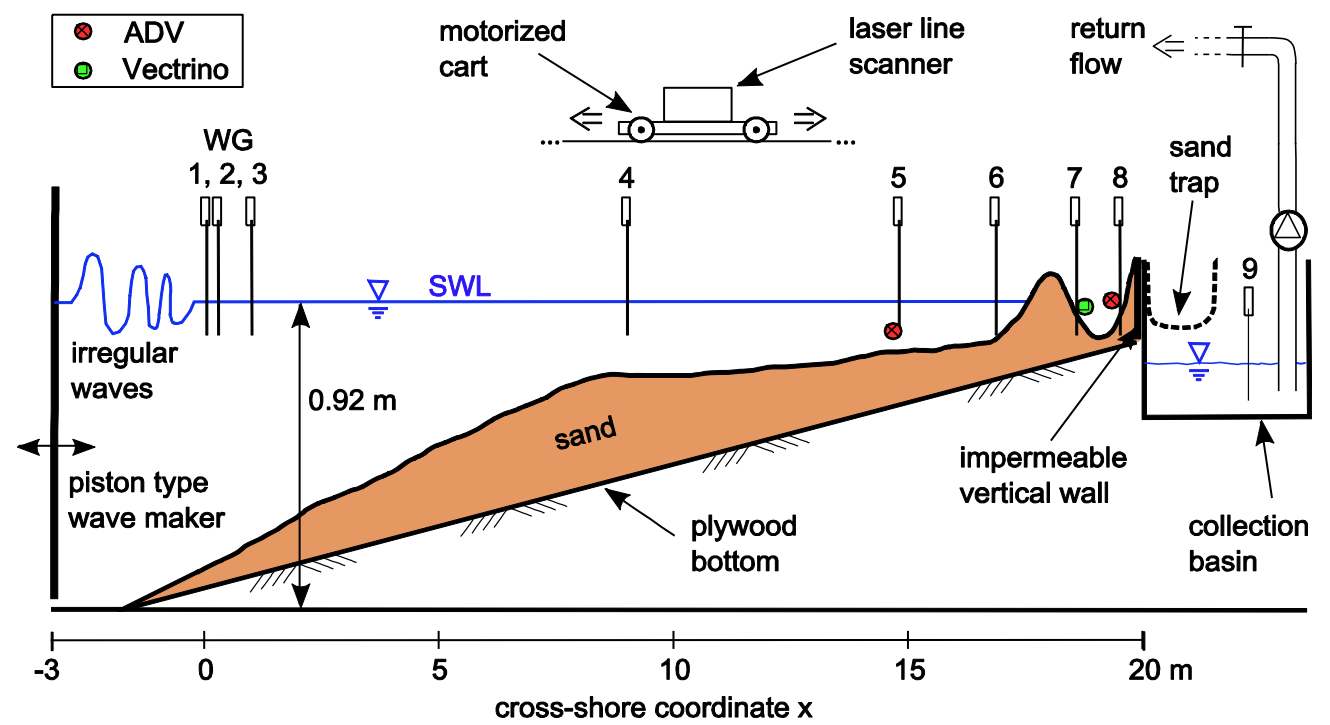

Figure 3. Schematic side view of the ridge-runnel experiment setup for the LR test including wave paddle, beach profile on top of plywood slope, laser line scanner on motorized cart, collection basin with sediment trap, water circulation system and measurement instrument locations.

In order to simulate the ridge-runnel scenario without rip channels, the LR profile and SWL were lowered by $8 \mathrm{~cm}$ compared to the HR test. This prevented wave overtopping over the vertical wall at the landward end of the runnel and ensured runnel drainage by offshore return current over the ridge only. The initial ridge crest in the LR test was $4 \mathrm{~cm}$ lower than the vertical wall crest. The first run of each test started out with the RWL being equal to the SWL. Even though at the end of each run the runnel had to be drained for laser profile measurements, the continuity of the entire ridge-runnel migration test was accomplished by starting the RWL at the same level as measured during the end of the previous run. Each test stopped after the ridge-runnel system had completely dissolved into a nearequilibrium profile. In fact, for the LR test, equilibrium was reached but the HR profile was still in an erosive state at the end of the test due to continued overtopping and overwash of the vertical wall. Since ridge migration was much faster in the HR test because of the drainage effect, only ten 400-s runs $(4,000 \mathrm{~s}$ total $)$ were required compared to thirty-five runs $(14,000 \mathrm{~s}$ total $)$ for the LR test. On average, the reflection coefficient $\mathrm{R}$ was on the order of $10 \%$ for both tests. Table 1 gives a summary of the HR and LR tests.

\begin{tabular}{|l|c|c|}
\hline \multicolumn{2}{|c|}{ Table 1. Summary for HR and LR tests. } \\
\hline \multicolumn{1}{|c|}{ Test } & HR & LR \\
\hline number of runs & 10 & 35 \\
$\mathrm{H}_{\text {mo }}(\mathrm{cm})$ & 18.2 & 17.8 \\
$\mathrm{H}_{\mathrm{rms}}(\mathrm{cm})$ & 12.8 & 12.6 \\
$\mathrm{H}_{\mathrm{s}}(\mathrm{cm})$ & 17.9 & 17.5 \\
$\mathrm{~T}_{\mathrm{p}}(\mathrm{s})$ & 2.6 & 2.6 \\
$\mathrm{~T}_{\mathrm{s}}(\mathrm{s})$ & 2.3 & 2.3 \\
$\mathrm{R}$ & 0.11 & 0.10 \\
\hline
\end{tabular}

\section{Bottom Profiling}

Sand bottom evolution was measured using two different profiling systems. A class III Acuity AR4000-LIR laser line scanner system mounted on a motorized cart recorded longshore transects at 2$\mathrm{cm}$ cross-shore intervals yielding $3 \mathrm{D}$ morphology information of the entire subaerial portion of the bed. 
This portion was artificially extended to the range of $x=6-20 \mathrm{~m}$ by lowering the water level in front of and inside the runnel after each run. The laser system obtains distance measurements via a time-offlight measurement of the emitted laser beam reflected from a target. The main components of the AR4000 line scanner system are the horizontally mounted $780 \mathrm{~nm}$ IR laser diode with an optical power output of $8 \mathrm{~mW}$ and a rotating mirror assembly which deflects the outgoing and reflected laser beam by $90^{\circ}$ to allow for a $2 \mathrm{D}$ scan of the vertical (y-z) plane during a full $360^{\circ}$ sweep of the mirror around its horizontal axis. Performance and measurement accuracy depend on a variety of factors like distance from the target, amplitude of the return signal (reflectivity of the target), and three types of noise including detector thermal noise, laser diode noise, and noise related to the chosen sampling resolution. The line scanner has a maximum range of $9 \mathrm{~m}$ but is configured with a close focus optics option which yields the greatest measurement sensitivity around $1 \mathrm{~m}$ from the sensor, consistent with the required range of $0.5-1.5 \mathrm{~m}$ in the experiment.

Fine sand has good diffuse reflective properties leading to high return signal amplitudes in the detection photo diode. This ensures very accurate readings but the three types of noise that can affect the standard deviation of the return signal vary depending on the sampling rate. The AR4000 line scanner is connected to a PC via a high speed interface card capable of sampling distance measurements at a rate of 50,000 Hz. For the present application the sampling rate was set to $10,000 \mathrm{~Hz}$ which yields a root-mean-square noise value of approximately $1.5 \mathrm{~mm}$ mainly related to drift and fluctuation of the emitted laser beam (laser diode noise). In order to create 3D images of the surface scanned by the $(y-z)$ line scanner, the line scanner system was mounted on a motorized cart moving along the flume's x-axis on a set of T-tracks. Care was taken to arrange the line scanner in such a way that the axes of mirror rotation and emitted laser beam coincide with the centerline (x-axis) of the flume so that one sweep of the mirror yields distance measurements of an alongshore slice of the flume topography.

The cart is equipped with a servo motor and control unit capable of moving the line scanner back and forth in the cross-shore direction with continuously adjustable speeds up to $10 \mathrm{~cm} / \mathrm{s}$ per second. The $\mathrm{x}$-coordinate of the 2D slice scanned by the line scanner at any point along the flume is provided by a stationary AR1000 distance sensor. This laser range finder emits a horizontal beam of visible red light $(650 \mathrm{~nm})$ with optical power output of $1 \mathrm{~mW}$. It measures the distance from its fixed position next to the collection basin to the moving cart. A portion of the light scattered from a reflective target mounted on the motorized cart is collected and focused on a photo detector inside the AR1000 to calculate the distance of the target from the fixed position of the range finder via the time-of-flight method.

During a scan the cart is moving at a constant speed of $1 \mathrm{~cm} / \mathrm{s}$ while the line scanner does sweeps of alongshore slices in a fraction of a second at set cross-shore increments controlled by the AR1000 distance sensor. The scanned alongshore slices are practically perpendicular to the $\mathrm{x}$-axis since the slow translatory motion of the cart during an entire $360^{\circ}$ sweep of the line scanner is negligible compared to the high speed rotation of the mirror. For this experiment the line scanner has been configured to collect 500 data points per alongshore slice at a sampling frequency of $10,000 \mathrm{~Hz}$ which corresponds to a measurement time of $0.05 \mathrm{~s}$ per slice. Alongshore slices are measured every $2 \mathrm{~cm}$ over a length of $14 \mathrm{~m}$ in this experiment which leads to an overall time of 20 minutes required for one complete scan. Fig. 4 shows 3D laser scan results in the zone of major profile change at various time steps during the HR and LR tests.

An array of three submerged ultrasonic transducers recorded three cross-shore transects of the remaining underwater portion of the profile. Profile changes were clearly discernible landward of $x=$ $15.5 \mathrm{~m}$. For the analysis, the 3D morphology data was checked thoroughly to verify longshore uniformity before reducing the data to an average $2 \mathrm{D}$ cross-shore profile.

\section{DATA ANALYSIS}

The mean value of the free surface elevation $\bar{\eta}$ and its standard deviation $\sigma_{\eta}$ were extracted from the time series recorded by WG1 - WG8 for every 400-s run. WG7 and WG8 were initially located inside the runnel but entered the intermittently wet and dry regime as the ridge crest migrated onshore and the runnel was filled with sediment. A modified analysis procedure for WG7 and WG8 allowed for additional information on runnel water depth $h_{r}$ and wet probability $P_{w}$ at these locations with rapidly changing profile elevations in addition to the usual free surface elevation. The velocity time series from the two ADVs and the Vectrino probe provide a better understanding of the complicated flow patterns over the ridge crest (very small water depths) and inside the runnel (water pond). 


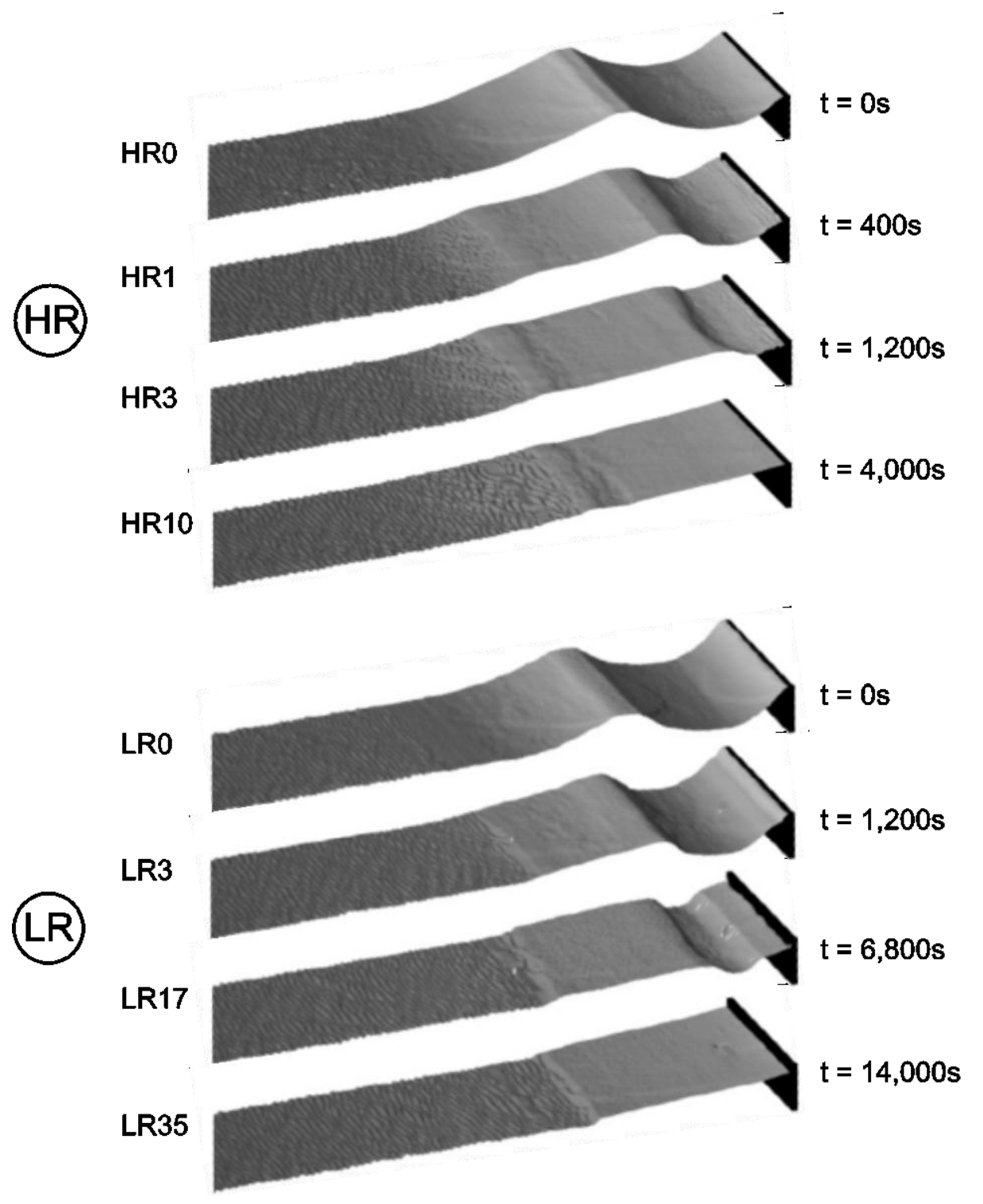

Figure 4. Measured nearshore portions of 3D bottom scans for the HR and LR test at select time steps. These detailed scans were recorded via the AR4000 laser line scanner system.

In the left panel of Fig. 5 the WG and ADV placements for the HR and LR tests are shown for the near-shore region which includes the area of major profile change. The ridge-runnel evolution is visualized by three profiles measured during the HR (top panel) and LR (bottom panel) tests. These major profile changes required adjustment of the vertical position of the velocity measuring volumes (circles) in order to capture flow velocities in very small water depths.

The image in the right panel of Fig. 5 shows the initial instrumentation setup for the LR test. WG7 and the Vectrino probe are located near the shoreward end of the runnel whereas WG8 and ADV2 are located closer to the landward end of the runnel. This cross-shore placement ensures hydrodynamic measurements on the migrating ridge crest and in the runnel all the way up to its complete infilling with sediment.

\section{Bottom Profile Evolution and Overwash}

In both experiment test cases the observed ridge-runnel migration was onshore. However, the speed at which the ridge advanced onshore and closed up the runnel varied significantly between HR and LR. The ridge shape was modified by several mechanisms. Sediment eroded from the seaward ridge slope and ridge crest by wave up and down rush, offshore flow out of the runnel and undertow current. Deposition on the seaward end of the runnel was much more pronounced compared to deposition in 
other parts of the runnel. The ponded water acted as a settling basin for the incoming sediment over the ridge crest. The settling asymmetry in the runnel caused the apparent onshore migration of the ridge and the subsequent infilling of the runnel. Water and sediment could exit the runnel by offshore return flow over the ridge (HR and LR) or through wave overtopping and sediment overwash of the vertical wall at the landward end of the runnel (HR only).
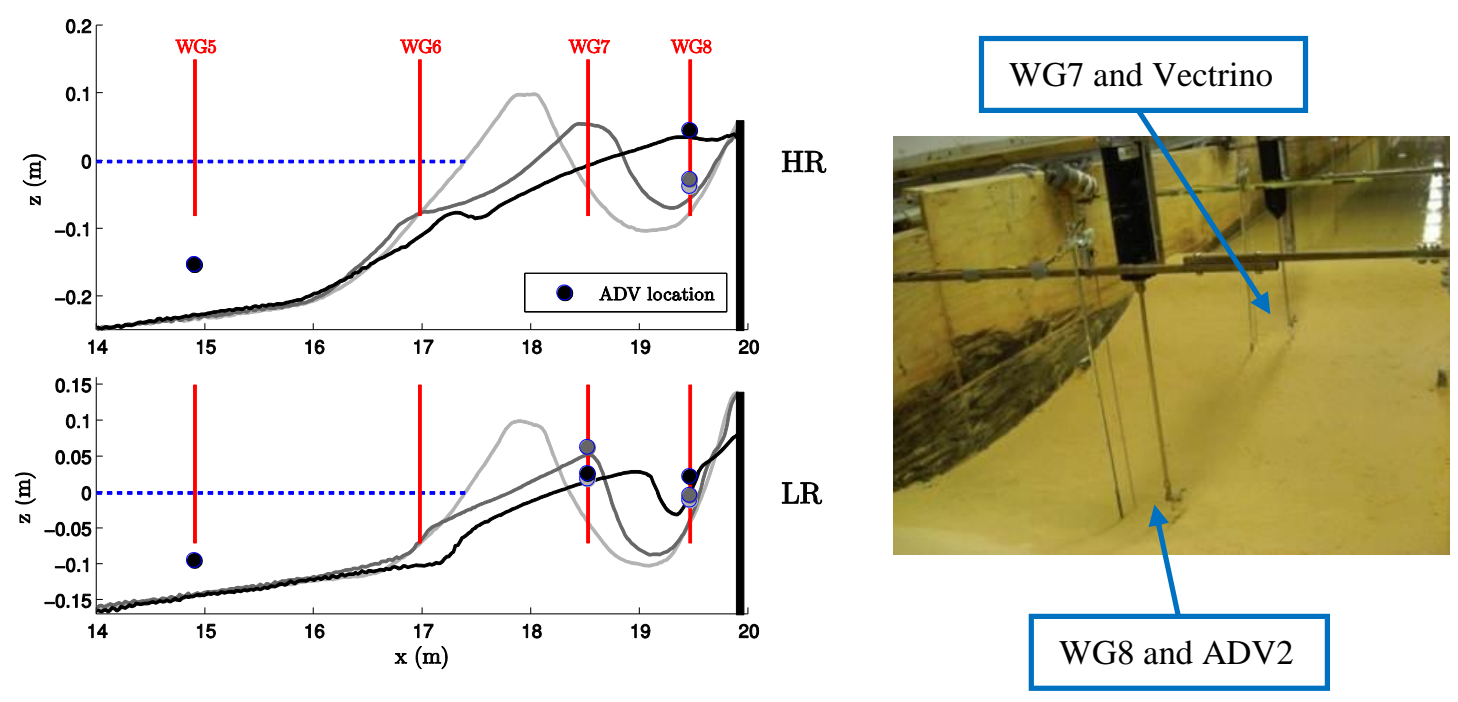

Figure 5. Left panel: WG and ADV placement during HR (top) and LR (bottom) tests. Cross-shore locations of WGs (red vertical lines) and ADVs (circles) remained fixed. The vertical position of the ADV measuring volumes varied with bottom profile elevation. Right panel: Photo of initial LR test setup showing WG7 together with the Vectrino and WG8 together with ADV2 all located inside the runnel.

The left panels in Fig. 6 show the measured ridge-runnel profiles in the zone of major profile changes $(15.5<\mathrm{x}<19.9 \mathrm{~m})$ in front of the vertical wall for the HR and LR tests. Profile changes offshore of this zone were negligible. Bottom elevations are in reference to the respective SWL for each test. Colors from green to red indicate the evolution from initial to final profile. A total of eleven HR profiles were scanned before the test and after each run (HR0 - HR10) to capture the rapid ridge-runnel migration. Twelve profile measurements captured the slower morphological evolution in the LR test (LR0, 1-4, 6, 9, 13, 17, 23, 29, 35).

As the ridge is lowered by wave action and the runnel fills up with water, the offshore directed backflow over the ridge increases in importance. The right panel of Fig. 6 shows the overwash transport rate $q_{b s}$ the wave overtopping rate $q_{o}$ and their ratio for the HR test at the location of the vertical wall. Initially, $q_{b s}$ is very small but shows a sudden increase to $0.2 \mathrm{~cm}^{2} / \mathrm{s}$ after passing the 2000 -s mark since at that point the runnel has been almost completely eliminated and cannot act as a sediment sink any more. Subsequently, all the sediment transported landward passed the vertical wall. Hence, the final overwash transport rate may also serve as an estimate for the sediment transport rate over the ridge. The $q_{o}$ evolution is initially influenced by the crest height of the ridge since a high ridge limits offshore backflow. As the crest height diminishes, so does $q_{o}$. A minimum of $10 \mathrm{~cm}^{2} / \mathrm{s}$ is reached in run HR4, followed by a slight increase in $q_{o}$ up to a constant level of approximately $12 \mathrm{~cm}^{2} / \mathrm{s}$ until the end of the test. The steady decrease from HR1 to HR4 is related to the changing elevation difference between the ridge crest and fixed vertical wall.

During the initial run waves overtopped the ridge, increased the RWL and caused maximum crest lowering and onshore ridge migration. Once the runnel was filled with water, the morphological evolution for HR and LR started to differ significantly due to the different boundary conditions at the landward end of the runnel. In the HR test a terrace formed at the foot of the seaward ridge slope migrating onshore at a rate of $1 \mathrm{~cm} / \mathrm{min}$. The ridge-runnel feature maintained its relative shape but the distance between the crest and trough reduced until it merged completely into a 1/14 beach slope in run HR6. A step formed at the foot of the seaward LR ridge slope. The seaward ridge slope flattened before merging into a $1 / 15$ beach as the ridge crest was lowered during onshore migration. The characteristic slip-face at the seaward end of the runnel steepened up to a slope of 1/5 in LR17 mainly due to the 
strong influence of the offshore flow out of the runnel which limited deposition at the landward end of the runnel. We chose three distinct phases of ridge-runnel evolution based on the measured profile shapes.
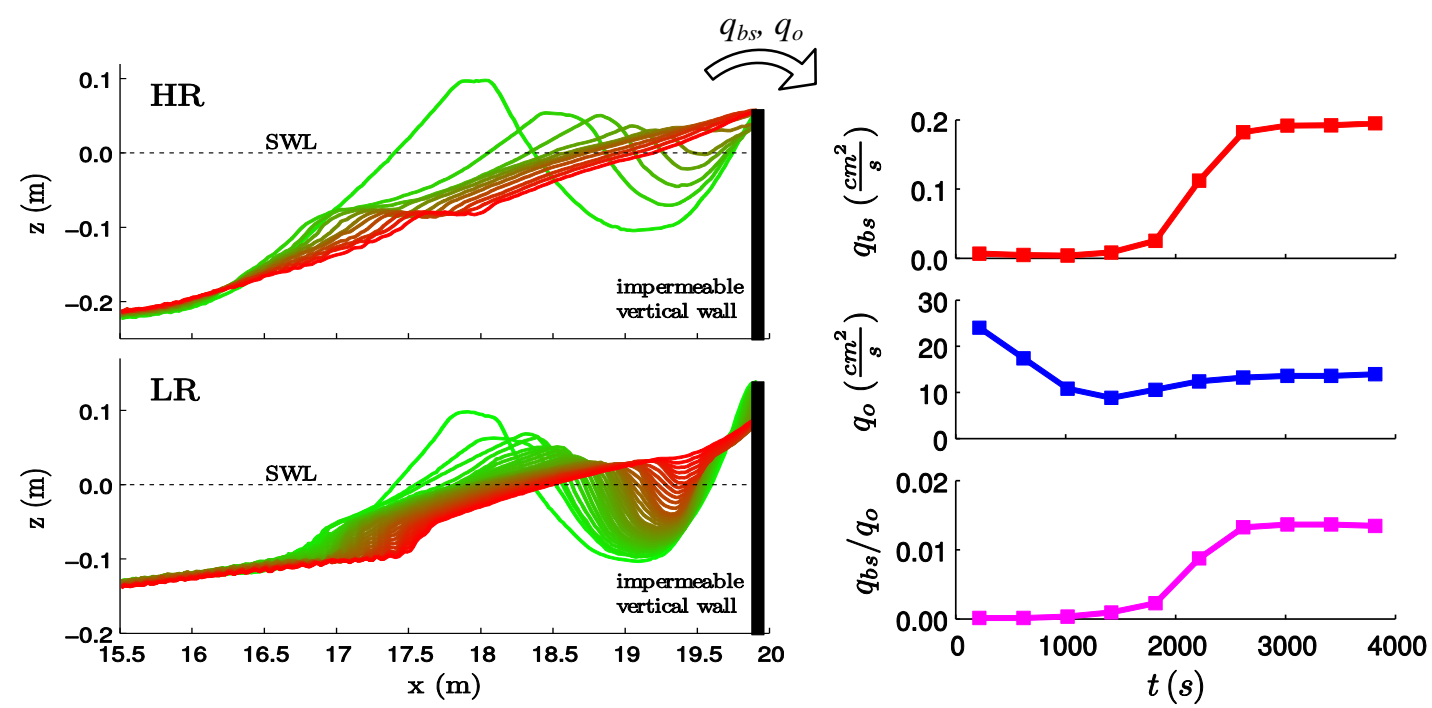

Figure 6. Left panels: Ridge-runnel evolution in the zone of major profile changes measured for HR (top) and LR (bottom). A color map from green (initial) to red (final) indicates the profile changes over time. Right panels: Measured sand transport rate $q_{b s}$ (bedload + suspended load) in red and water transport rate $q_{o}$ in blue as a function of time $t$ for the HR test. Their ratio is depicted in the bottom plot (magenta). Data points are averages over the respective 400-s run. By design no significant wave overtopping and sediment overwash occurred during LR.

Phase 1: The seaward ridge slope adjusts to the forcing conditions by forming a concave beach profile. Waves overtop the ridge crest, fill up the runnel, lower the crest elevation significantly, and transport a relatively large amount of sediment into the runnel, leading to rapid onshore ridge migration. Offshore flow over the ridge is initiated after the runnel is filled up (HR1, LR1).

Phase 2: Onshore migration and progressive reduction of the ridge-runnel cross-sectional area. The rate of the ridge-runnel profile evolution is influenced by the wave-induced water flow into and out of the runnel. The runnel is always filled with water (HR2 - HR5, LR2 - LR33).

Phase 3: Profile evolution of a sloping beach in front of the wall after the ridge-runnel system is completely smoothed out (HR6 - HR10, LR34 - LR35).

Fig. 7 gives a visual display of the HR (top panel) and LR (bottom panel) measured profiles separating the three phases for each test, respectively. It becomes apparent that the ridge migration phase 2 is significantly longer in the LR test due to the increased offshore backflow of water and sediment over the ridge compared to the HR test. In fact, the ridge migration during HR is five times faster than during LR.

\section{Measured Hydrodynamics}

Free surface elevation $\eta$ and the three components of the flow velocity $(u, v, w)$ were measured via wave gauges and ADVs as explained in the experiment setup section. The time series used to calculate the mean and standard deviation of these values consisted of individual 400-s runs. For each run record the initial 20-s ramp-up period was discarded to eliminate its effect on the hydrodynamic statistics. Free surface elevation is given by $\eta=\left(h+z_{b}\right)$ where $h$ is the instantaneous water depth and $z_{b}$ is the local bottom elevation which is negative below SWL. The time series from WG1-WG3 allowed us to separate incident and reflected signals at the location of WG1 and confirmed run repeatability. The spectral significant wave height $H_{m 0}$, the root-mean-square wave height $H_{r m s}$, and the spectral peak period $T_{p}$ were derived from the incident wave energy spectrum whereas the significant wave height $H_{s}$ and the significant period $T_{s}$ were calculated using the zero upcrossing method explained by Goda (2000). Table 1 lists the average value of these incident wave parameters over all the runs in each test.

WG1 through WG4 records revealed setdown (negative $\bar{\eta}$ ) in all runs whereas WG6 through WG8 records always showed setup. WG7 and WG8 yielded larger wave setup values up to $7 \mathrm{~cm}$ 
because the two gauges were located in the intermittently wet and dry zone of the migrating ridgerunnel system and the measured free surface elevation included RWL fluctuations and rapid profile changes. Waves were observed to be breaking in the vicinity of WG4 and WG5.

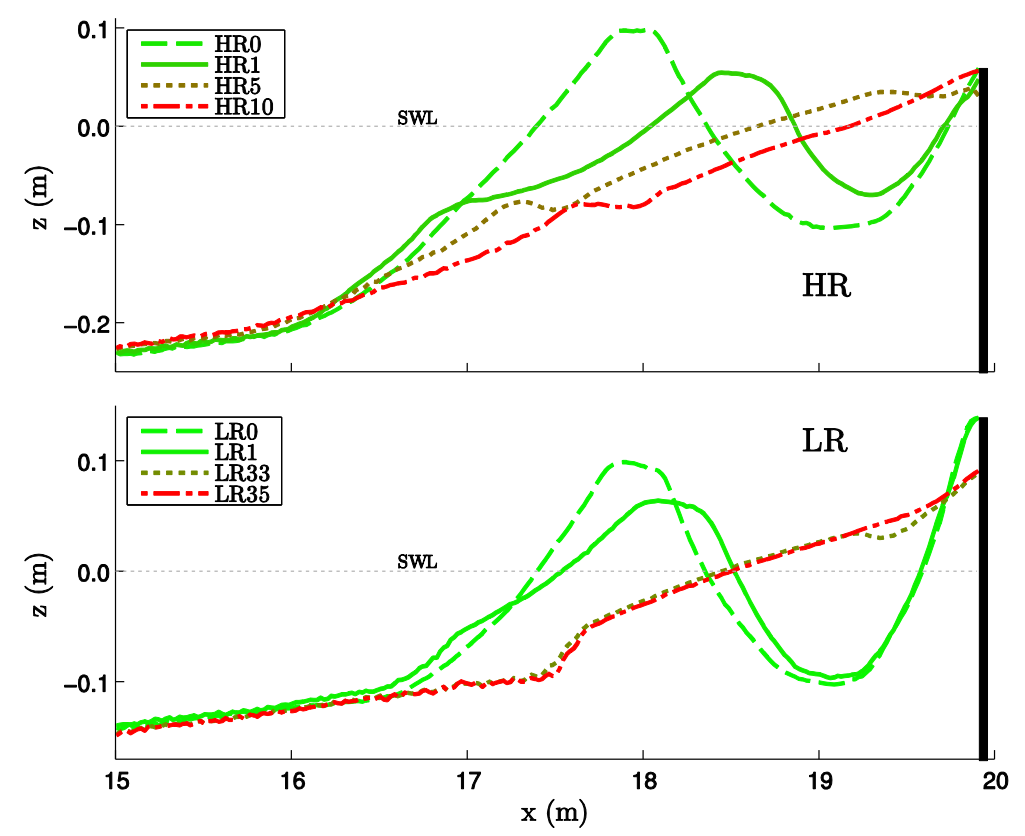

Figure 7. Measured HR (top panel) and LR profiles (bottom panel) separating three evolution phases.

Fig. 8 shows the measured free surface elevation, runnel water level and bottom elevation at the WG7 and WG8 cross-shore locations for the entire HR test to give a detailed example of the recorded data and deducted statistical values during the ridge-runnel experiment. The displayed data indicate the evolution of the wave and runnel hydrodynamics in conjunction with rapid bottom changes as observed at a fixed cross-shore location.

Measured free surface elevation $\eta(t)$ is split up into wet duration and dry duration. The wet duration signal is shown as a dark blue fluctuating signal with integers denoting run numbers. The dry duration signal indicates the bottom elevation and is represented by green dots. The initial 20-s ramp-up period is removed from all runs as explained above. Yellow diamonds represent the mean free surface elevations during the wet duration in each run. In order to place the dry duration measurements in perspective, the measured bottom elevation at each gauge location is plotted as red circles. Red lines interpolating profile measurements from the laser line scanner and dry duration elevations from the wave gauge records match well. Estimates for runnel water level (RWL) obtained by spline interpolation of $\eta(t)$ are presented as cyan colored dashed lines for WG7 and WG8. The spline boundary condition at $t=0$ is set to zero since the initial RWL is equal to SWL. Rapid RWL increase is characteristic for the first run (phase 1) and is apparent in the WG7 and WG8 records. For the HR test RWL peaked in the middle of HR1 when the runnel was completely filled by wave overtopping. At this point the ridge crest elevation was already reduced to half its original height of $0.1 \mathrm{~m}$ and the ridge migrated onshore near WG7. Further ridge crest reduction lowered the RWL. After HR1, WG7 was on the seaward ridge slope. Starting in HR4, WG7 was submerged always with no dry duration. At the end of HR5 the runnel was filled in with sand. This can be observed in the WG8 time series where the measured bottom elevations (red circles) match up with the measured dry duration (green dots). During HR6 - HR8 multiple outliers in the WG8 record had to be removed, which explains the reduced wave peaks in those three runs. The outliers were caused by several high wave crests hitting the gauge.

The measured velocity data obtained from the ADVs in this two-dimensional wave flume experiment was dominated by the cross-shore component as was to be expected. In front of the ridge (seaward side) an undertow current directed offshore was always present as indicated by the mean cross-shore current values measured by ADV1 at $\mathrm{x}=14.9 \mathrm{~m}$. 

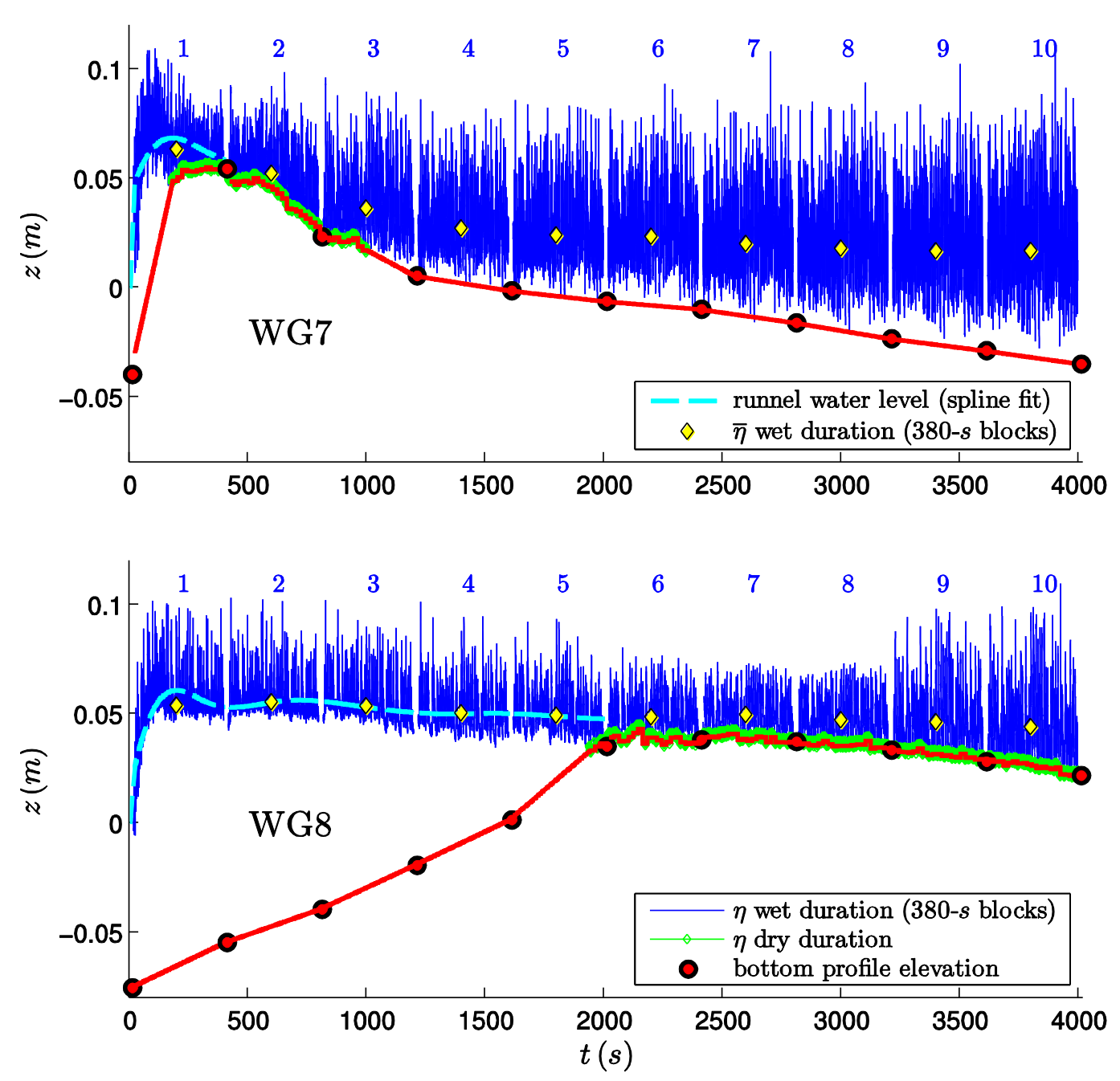

Figure 8. Measured free surface elevation (wet and dry duration, respectively), runnel water level, and bottom elevation at WG7 $(x=18.52 \mathrm{~m})$ and WG8 $(x=19.46 \mathrm{~m})$ locations for 10 runs of the HR test. Initially both gauges are located inside the runnel with water level equal to SWL. The initial 20-s ramp-up period in every run has been removed to create a gap between successive runs. The mean free surface elevation is displayed as yellow diamonds at the center of each 380 -s data interval.

ADV2 $(x=19.5 \mathrm{~m})$ was located inside the runnel during phases 1 and 2 before being subjected to intermittent exposure to air in phase 3 . With the exception of HR1 where the initially empty runnel filled in rapidly, the mean velocities remained rather low, fluctuating slightly around zero with magnitudes on the order of $1 \mathrm{~cm} / \mathrm{s}$. This result shows the deceleration effect of the ponded water on the flow velocity. After the runnel had disappeared the mean cross-shore velocity became positive (onshore) and increased significantly to a maximum of $8.6 \mathrm{~cm} / \mathrm{s}$. These measurements are consistent with the measured net onshore transport due to overwash in the HR test. For the LR test ADV2 was submerged inside the runnel during LR1 - LR32. Mean cross-shore velocities were slightly negative with magnitudes rarely exceeding $1 \mathrm{~cm} / \mathrm{s}$, possibly related to a small return flow inside the runnel. At the end of the LR test an offshore directed mean cross-shore velocity was detected at the location of ADV2 due to the fact that the runnel had disappeared and the instrument was now located on the sloping beach face in front of the wall. The wall prevented overtopping flow in the LR test which explains this measured offshore return flow.

As indicated in the lower left panel of Fig. 5 the Vectrino probe at $x=18.5 \mathrm{~m}$ started out inside the runnel. The probe then encountered the onshore migrating ridge requiring the probe to be adjusted vertically before each run. The most adverse measuring conditions occurred with the probe being 
positioned directly on top of the ridge crest where it was exposed to air up to $75 \%$ of the time and on the seaward ridge slope where it was exposed to air up to $50 \%$ of the time. Only the data during the wet duration were used. The mean cross-shore velocity was predominantly directed offshore and ranged between 0.5 and $-9.4 \mathrm{~cm} / \mathrm{s}$. The largest offshore current was detected at the end of LR with the Vectrino being located in the swash zone of the sloping beach. In general, the longshore mean velocity component measured by the Vectrino was an order of magnitude lower than its cross-shore counterpart.

\section{NUMERICAL TREATMENT OF RIDGE-RUNNEL EXPERIMENT}

The sediment transport module of the numerical cross-shore model CSHORE (Kobayashi et al., 2009) has been extended based on the presented experiments to include the capability to compute beach profile changes and transport rates when a ridge-runnel system is present. A modified continuity equation now takes into account the effect of ponded water in the runnel. Furthermore, the net onshore sediment transport in the runnel is reduced via an exponential reduction factor to mimic sediment settling in the runnel on its seaward end. The model has been successfully employed to compute beach profile changes including dune overwash events (Figlus et al., 2011) and also shows promising results for the computation of ridge-runnel migration (Figlus et al., 2012). In the following, further information on the CSHORE upgrade related to ridge-runnel migration is given to supplement the information supplied by Figlus et al., (2012).

The extension of the time-averaged model CSHORE includes ponding effects as created by a runnel forming on the beach. Such a dip in the profile collects water and affects the local sediment transport dynamics. A more in-depth description of the program modifications is given in the report of Figlus et al. (2010). CSHORE is used to predict the cross-shore variations of the mean free surface elevation $\bar{\eta}$, the free surface standard deviation $\sigma_{\eta}$, the depth-averaged cross-shore current $\bar{U}$, the cross-shore velocity standard deviation $\sigma_{U}$, the wet probability $P_{w}$, the cross-shore bed-load transport rate $q_{b}$, and the cross-shore suspended sediment transport rate $q_{s}$ on an arbitrary bottom profile. It combines a model for the wet zone based on the Gaussian probability distribution of $\eta$ and linear wave theory (Kobayashi et al. 2009) with a model for the intermittently wet and dry zone above SWL based on the time-averaged continuity and momentum equations derived from nonlinear shallow-water wave equations (Kobayashi et al. 2010). Probabilistic averaging is performed only during $h>0$. The probability density function of the water depth $h$ in the wet and dry zone is assumed to be exponential and the wet probability $P_{w}$ is defined as the probability of $h>0$. Figlus et al. (2011) included wave overtopping and sediment overwash of dunes in CSHORE but the effect of ponded water was neglected for lack of data.

The CSHORE definition sketch in Fig. 9 shows the transition from the wet model $\left(x<x_{r}\right)$ below mean water level (MWL) to the wet and dry model $\left(x>x_{1}\right)$ above SWL including storm tide $S$ where $S$ $=0$ in this experiment. In the runnel between the ridge crest $\left(x_{c}, z_{c}\right)$ and landward end $\left(x_{m}, z_{m}\right)$, water is ponded in the zone of $x_{w}<x<x_{2}$ with RWL at $z=z_{w}$ where $z_{w}$ is assumed to be horizontal and independent of $x$. The fine sand beach is assumed to be impermeable. The time averaged volume flux $q$ over the ridge crest and landward end is denoted as $q_{c}$ and $q_{m}$, respectively. In the ponded zone $q$ varies linearly with $x$ using the continuity equation of water for the ponded water zone

$$
\frac{d z_{w}}{d t}=-\frac{d q}{d x} \quad \text { for } x_{w} \leq x \leq x_{2}
$$

with

$$
\begin{array}{ll}
q=q_{c} & \text { for } 0 \leq x<x_{w} \\
q=q_{c}-\left(\frac{x-x_{w}}{x_{2}-x_{w}}\right)\left(q_{c}-q_{m}\right) & \text { for } x_{w} \leq x \leq x_{2} \\
q=q_{m} & \text { for } x_{2}<x \leq x_{m}
\end{array}
$$

where $q$ is equal to $q_{c}$ and $q_{m}$ seaward and landward of the ponded water zone, respectively.

The volume flux $q$ in the wet and dry zone is given by

$$
q=\frac{3 \sqrt{\pi} \alpha}{4} \bar{h}\left(\frac{g \bar{h}}{P_{w}}\right)^{0.5}+U_{s} \bar{h}
$$

where $\alpha=1.6$ is calibrated for wave overtopping of sand dunes (Figlus et al. 2011) and the steady velocity $U_{s}$ is included to account for offshore return flow on the seaward slope and downward velocity 
increase on the landward slope. The condition of $U_{s}=0$ on the ridge crest $\left(x=x_{c}\right)$ and at the landward end $\left(x=x_{m}\right)$ is imposed to estimate $q_{c}$ and $q_{m}$ if no overflow occurs at the peaks of the bottom elevation. The ponded water level $z_{w}$ is computed using $d z_{w} d t=\left(q_{c}-q_{m}\right) /\left(x_{2}-x_{w}\right)$ derived from Eqs. (1) and (2). The computed $z_{w}$ is adjusted to allow overflow at $x=x_{c}$ or $x_{m}$, depending on the elevations of $z_{c}, z_{w}$, and $z_{m}$. If overflow occurs at $x=x_{c}, z_{w}=z_{c}$ and $q_{c}=q_{m}$ with $U_{s}=0$ at $x_{m}$ only. If overflow occurs at $x=x_{m}$, $z_{w}=z_{m}$ and $q_{m}=q_{c}$ with $U_{\mathrm{s}}=0$ at $x=x_{c}$ only. For the hydrodynamic computation the ponded water zone is treated as a part of the wet and dry zone apart from the spatial variation of $q$ given by Eq. (2).

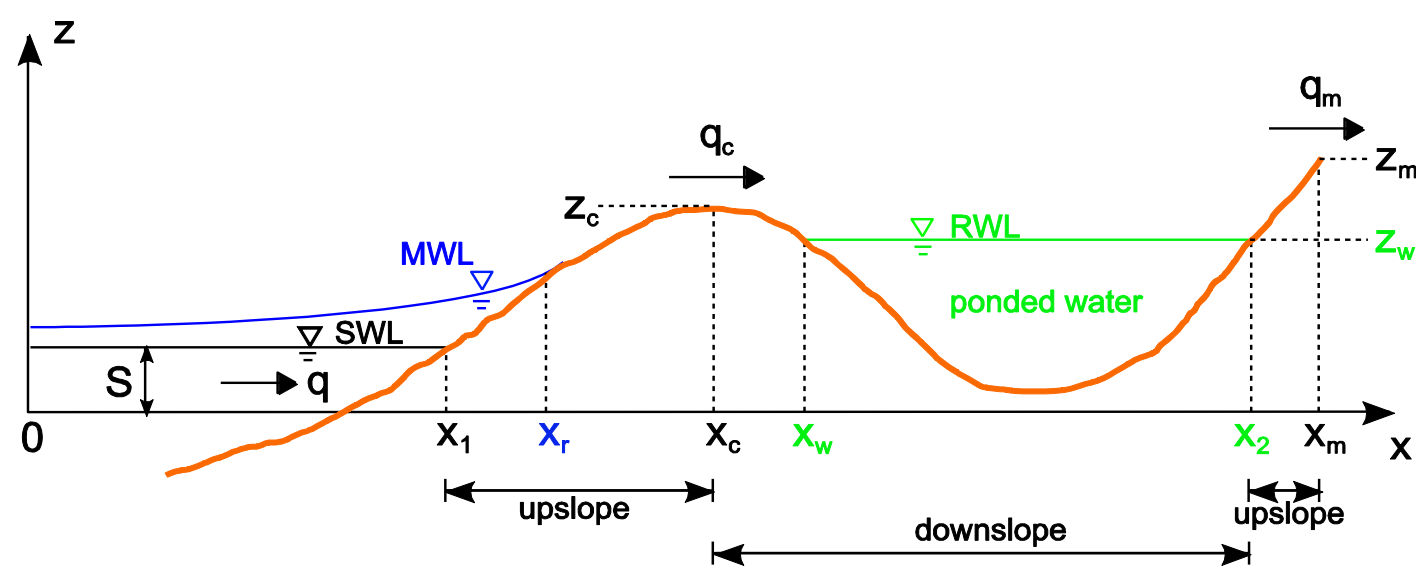

Figure 9. CSHORE definition sketch including the transition from wet model $\left(x<x_{r}\right)$ to wet and dry model $(x$ $\left.>x_{1}\right)$ and water ponding $\left(x_{w}<x<x_{2}\right)$ with runnel water level (RWL) at $z=z_{w}$ where the ridge crest and the landward end point are located at $\left(x_{c}, z_{c}\right)$ and $\left(x_{m}, z_{m}\right)$, respectively.

The sediment transport rates $q_{b}$ and $q_{s}$ are predicted using the same formulas in the entire computation domain so that $q_{b}$ and $q_{s}$ are continuous at the SWL shoreline (Kobayashi et al. 2010). The continuity equation of bottom sediment is solved numerically to obtain the bottom elevation at the next time level. Figlus et al. (2011) added an overwash term with an empirical overwash parameter $a_{o}$ to the formula for suspended sediment transport over a sand dune during major wave overtopping and overwash. The calibrated value of $a_{o}$ was approximately 3.3 and $a_{o}=3.3$ is used here.

The probability $P_{b}$ of sediment movement is obtained for the probability distribution of the instantaneous velocity $U$ as explained by Kobayashi et al. (2010). The movement of sediment particles represented by the median diameter $d_{50}$ is assumed to occur when the instantaneous bottom shear stress given by $0.5 \rho f_{b} U^{2}$ exceeds the critical shear stress $\rho g(s-1) d_{50} \psi_{c}$ with the Shields parameter $\psi_{c}=0.05$. The probability $P_{b}$ of sediment movement is then the same as the probability of $|U|>U_{c b}$ with $U_{c b}=\left[2 g(s-1) d_{50} \psi_{c} f_{b}^{-1}\right]^{0.5}$ and is given by

$$
\begin{array}{cc}
P_{b}=P_{w} & \text { for } U_{s}>U_{c b} \\
P_{b}=P_{w} \exp \left[-\frac{P_{w}\left(U_{c b}-U_{s}\right)^{2}}{\alpha^{2} g \bar{h}}\right] & \text { for }\left|U_{s}\right| \leq U_{c b} \\
P_{b}=P_{w}\left\{1-\exp \left[-\frac{P_{w}\left(U_{c b}+U_{s}\right)^{2}}{\alpha^{2} g \bar{h}}\right]+\exp \left[-\frac{P_{w}\left(U_{c b}-U_{s}\right)^{2}}{\alpha^{2} g \bar{h}}\right]\right\} & \text { for }-U_{s}>U_{c b}
\end{array}
$$

where the upper limit of $P_{b}$ is the wet probability $P_{w}$ because no sediment movement occurs during the dry duration. On the other hand, sediment suspension is assumed to occur when the instantaneous turbulent velocity estimated as $\left(f_{b} / 2\right)^{1 / 3}|U|$ exceeds the sediment fall velocity $w_{f}$ The probability $P_{s}$ of sediment suspension is then the same as the probability of $|U|>U_{c s}$ where $U_{c s}=w_{f}\left(2 / f_{b}\right)^{1 / 3}$. The probability $P_{s}$ is given by Eq. (4) with $U_{c b}$ replaced by $U_{c s}$. 
Ponded water acts as a small settling basin for sediment transported over the ridge crest. Sediment contained in the overtopping flow settles into the ponded water in the runnel. Offshore flow over the ridge occurs if the runnel is full but the offshore flow contains less sediment. This transport asymmetry promotes landward ridge migration as observed in the ridge-runnel experiment. If the ponding option is activated $(I P O N D=1)$, this transport asymmetry is taken into account by introducing the exponential reduction factor $R_{p}$ in the net sediment transport rate to reduce sediment transport inside the runnel and cause deposition near the seaward end of the runnel. The reduction factor $R_{p}$ due to ponded water is simply expressed as

$$
R_{p}=\exp \left(-\frac{x-x_{w}}{L_{d}}\right) ; \quad L_{d}=\frac{x_{2}-x_{w}}{a_{o}} \quad \text { for } x>x_{w}
$$

where the depositional length scale $L_{d}$ is related to the width $\left(x_{2}-x_{w}\right)$ of the ponded water surface. The overwash parameter $a_{o}$ is adopted as an empirical parameter for $L_{d}$ to reduce the number of empirical parameters. The reduction factor is applied to the bedload and suspended load transport rates $\left(q_{b}, q_{s}\right)$. These empirical adjustments are necessary to properly represent the complicated hydrodynamics and sediment transport processes observed during ridge-runnel migration.

For a detailed comparison of the CSHORE computations with the measured data the reader is referred to Figlus et al. (2010) and Figlus et al. (2012). As an example and in order to show the impact of the CSHORE ridge-runnel modifications, the comparison of three measured and computed bottom profiles for the HR and LR test, respectively, are shown in Fig. 10. In the left panels three representative HR runs are displayed. The thin and thick grey lines represent the initial and measured profiles, respectively. In addition, two versions of the CSHORE computation results are presented for each panel. The red dashed line solution is computed without taking into account the effect of the ponded water in the runnel $(I P O N D=0)$. It becomes apparent that deposition of sediment into the runnel and onshore ridge migration are not represented well. The blue dotted line solution $(I P O N D=1)$ includes the above described modifications for ponded water and shows a dramatic improvement of the profile results. Onshore ridge migration is predicted well by progressive infilling of the runnel on the landward side of the ridge with sediment eroded from its seaward side. Phase 3 still poses some computational problems due to the influence of the vertical wall which is overtopped in the HR test but completely blocks all landward water and sand transport in the LR test.

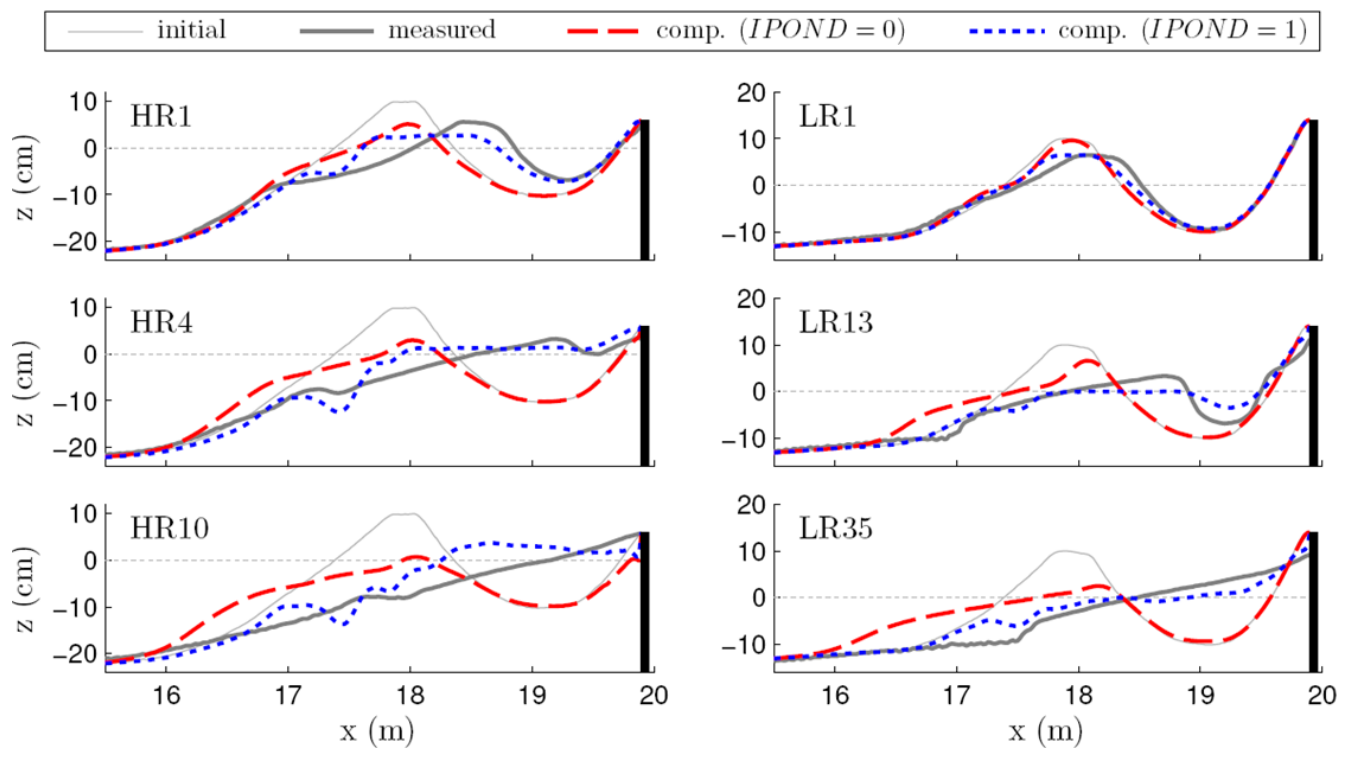

Figure 10. Measured and computed ridge-runnel profiles for three runs of the HR (left) and LR (right) tests. The figure has been adapted from Figlus et al. (2012).

\section{CONCLUSIONS}

Beaches may recover after storms via onshore ridge-runnel migration. The present laboratory flume investigation focused on purely wave induced ridge-runnel migration. Two different scenarios commonly found on real beaches were replicated in a mobile bed wave flume by two test series. The main difference between the two tests was the way water and sediment collected in the runnel were able 
to exit that runnel. In the HR test water and sediment could exit the runnel either by wave overtopping and overwash over a vertical wall at the landward end of the runnel or as offshore return flow over the ridge. This was intended to mimic a 3D return flow scenario on real beaches where water and sediment are able to leave the runnel through rip channels intersecting the ridge at certain longshore intervals in addition to the offshore return flow over the ridge. In the LR test water and sediment could only exit the runnel as offshore return flow over the ridge. The HR test setup resulted in a ridge migration speed five times faster than that of the LR test setup. This implies that beaches with drained ridge-runnel systems (e.g. via rip channels) may be able to recover significantly faster from storm induced erosion than beaches that are alongshore uniform.

Three distinct phases of the onshore ridge-runnel migration were identified based on profile evolution characteristics in the experiment. During phase 1 the initial infilling of the runnel with water took place. In phase 2 onshore ridge migration occurred as the runnel filled in from its seaward side by sediment transported over the ridge. Phase 3 occurred after the runnel was completely filled in and only a sloping beach in front of the vertical wall was left. A modified version of the numerical model CSHORE provided good agreement with measured ridge-runnel profile measurements during phases 1 and 2 but will require further improvement during phase 3 where the wall effects become more dominant.

\section{ACKNOWLEDGMENTS}

This project was supported by the U.S. Army Engineer Research and Development Center.

\section{REFERENCES}

Aagaard, T., M. Hughes, R. Møller-Sørensen, and S. Andersen. 2006. Hydrodynamics and sediment fluxes across an onshore migrating intertidal bar, J. Coastal Res., 22(2), 247-259.

de Vriend, H.J., M. Capobianco, T. Chesher, H.E. de Swart, B. Latteux, and M.J.F. Stive. 1993. Approaches to long-term modelling of coastal morphology: a review. Coastal Engineering, 21, 225-269.

Figlus, J., N. Kobayashi, and C. Gralher. 2012. Onshore migration of emerged ridge and ponded runnel. J. Waterway, Port, Coastal, Ocean Eng., 138(5), 331-338.

Figlus, J., N. Kobayashi, and C. Gralher. 2010. Ridge-runnel migration - experiment and numerical investigation. Research Report No. CACR-10-02, Center for Applied Coastal Research, Univ. of Delaware, Newark, Del.

Figlus, J., N. Kobayashi, C. Gralher, and V. Iranzo. 2011. Wave overtopping and overwash of dunes. $J$. Waterway, Port, Coastal, Ocean Eng., 137(1), 26-33.

Goda, Y. 2000. Random seas and design of maritime structures. World Scientific, Singapore, 443 pp.

Houser, C. and B. Greenwood. 2007. Onshore migration of a swash bar during a storm. J. Coastal Res., 23(1), 1-14.

Kobayashi, N., M. Buck, A. Payo, and B.D. Johnson. 2009. Berm and dune erosion during a storm. $J$. Waterway, Port, Coastal, Ocean Eng., 135(1), 1-10.

Kobayashi, N., A. Farhadzadeh, J.A. Melby, B.D. Johnson, and M. Gravens, 2010. Wave overtopping of levees and overwash of dunes. J. Coastal Res., 26(5), 888-900.

Masselink, G., A. Kroon, and R.G.D. Davidson-Arnott. 2006. Morphodynamics of intertidal bars in wave-dominated coastal settings - a review. J. Geomorphology, 73, 33-49.

Robin, N., F. Levoy, and O. Monfort. 2009. Short term morphodynamics of an intertidal bar on megatidal ebb delta. Marine Geology, 260, 102-120. 